\title{
Effect of Mobile-Phase Composition on Pressure-Induced Shifts in Solute Retention for LC Separations using $\beta$-Cyclodextrin Stationary Phases
}

\author{
Moira C. Ringo, Christine E. Evans \\ Chemistry Department, University of Michigan, Ann Arbor, MI 48109-1055, USA
}

Received 27 May 1997; accepted 25 February 1998

\begin{abstract}
Modest pressure ( $<350$ bars) has a significant impact on reversed-phase liquid chromatographic retention using $\beta$-cyclodextrin stationary phase. Demonstrated here for separations of the positional isomers of nitrophenol and naphthol as well as the enantiomers of hexobarbital and mephobarbital, the effect of small pressure perturbations on solute capacity factor ranges from +11 to $-14 \%$. These changes in retention arise from pressure-induced shifts in solute equilibria and are used to estimate the change in molar volume upon solute binding with $\beta$-cyclodextrin $\left(\Delta V_{\text {comp }}\right)$. In this article, the effect of the mobile phase on pressure-induced shifts in solute retention is examined. Mobile-phase composition is observed to have a significant influence on the change in solute capacity factor with pressure and therefore on $\Delta V_{\text {comp }}$. As the composition of water in the mobile phase increases, the change in partial molar volume of complexation is observed to become more positive for both positional isomer and chiral separations. Although these studies imply that changes in solvent composition have a general effect on the observed $\Delta V_{\text {comp }}$ and therefore on the change in pressure perturbation with solvent composition, it is clear that more studies are needed to establish the exact nature and breadth of this effect. (c) 1998 John Wiley \& Sons, Inc. J Micro Sep 10: 647-652, 1998
\end{abstract}

Key words: $\beta$-cyclodextrin; liquid chromatography; chiral separations; enantiomer

\section{INTRODUCTION}

The extensive use of $\beta$-cyclodextrin in chemical separations has been driven by its ability to exhibit highly selective interactions with a wide variety of compounds. The $\beta$-cyclodextrin molecule, composed of seven glucoside units in a toroidal geometry, possesses a rigid inner cavity capable of selective size and shape discrimination [1]. In addition, the larger rim of the cyclodextrin cavity contains chiral carbons capable of enantioselective interactions [2]. This combination of binding capabilities has led to its utilization in liquid chromatographic stationary phases [3-5]. Although the methods used to fabricate the phase vary, the stationary phase used in this investigation is synthesized by chemically attaching

Presented at the Nineteenth International Symposium on Capillary Chromatography and Electrophoresis, Wintergreen, VA, May 1997

Correspondence to: C. E. Evans

Contract grant sponsor: National Science Foundation; contract grant number: CHE-9707513

Contract grant sponsor: Eli Lilly Company $\beta$-cyclodextrin to a spherical silica gel support using a 3-glycidoxylsilane spacer arm [6]. Inclusion complexation of solute with $\beta$-cyclodextrin is believed to be the dominant retention mechanism of this stationary phase in the reversed-phase mode [5].

Although the temperature dependence of $\beta$ cyclodextrin bonded phase separations has been investigated [7-9], pressure has only recently been examined as a variable for retention [10-12]. Even as density and viscosity of polar mobile phases do not change significantly in this pressure range [13], modest pressures may impact the retention of solutes through shifts in equilibrium. In this article we examine the role of modest pressure $(<350$ bars $)$ on solute retention in $\beta$-cyclodextrin bonded phases in the reversed-phase mode. These studies focus on the effect of changes in mobile-phase composition on these pressure perturbations of retention.

\section{EXPERIMENTAL METHODS}

Chemicals. The $\alpha$ - and $\beta$-naphthol as well as $(R, S)$-hexobarbital (5-[1-cyclohexenyl]-1,5 dimethyl- 
barbituric acid) and ( $R, S)$-mephobarbital (5-ethyl1-methyl-5-phenylbarbituric acid) standards were obtained from Sigma (St. Louis, MO) while $o-, m-$, and $p$-nitrophenol standards were purchased from Aldrich (Milwaukee, WI). Mobile-phase solutions were prepared using distilled, deionized water (model Milli-Q UV Plus, Millipore, Bedford, MA) and high-purity methanol (Baxter Healthcare, Muskegon, MI). For the enantiomeric separations, the mobile phases were buffered with high-purity acetic acid (Aldrich) and high-performance liquid chromatography (HPLC) grade triethylamine (TEA) (Fisher, Fair Lawn, $\mathrm{NJ}$ ) with $\mathrm{pH}$ reported as the apparent $\mathrm{pH}$ of the hydroorganic mobile phase measured using a standard $\mathrm{pH}$ meter. All chemicals were used without further purification.

Chromatography. A high-pressure syringe pump (model 260D, Isco, Lincoln, NE) equipped with a high-precision pressure transducer $( \pm 1 \mathrm{psi})$ was used to deliver the mobile phase. The split-injection technique (split ratio $=81 \pm 8 ; V_{\text {inj }}=12 \mathrm{~nL}$ ) was employed with a $1-\mu \mathrm{L}$ internal volume injection valve (Valco Instruments, Houston, TX) to introduce analyte solutions (0.7-1.6 mM, dissolved in mobile phase) onto the column. The analytes were detected utilizing an absorbance detector (model UVIS-205, Linear, Chicago, IL) fitted with a high-pressure capillary flow cell (76 $\mu \mathrm{m}$ i.d. and $357 \mu \mathrm{m}$ o.d.; Polymicro Technologies, Phoenix, AZ).

The positional isomer and enantiomer studies each used single, packed capillary columns containing $\beta$-cyclodextrin bonded stationary phase (Cyclobond I 2000, Advanced Separations Technology, Whippany, NJ). These chromatographic columns were fabricated using fused-silica capillary $(251 \mu \mathrm{m}$ i.d. and $360 \mu \mathrm{m}$ o.d.; Polymicro Technologies, Phoenix, AZ) packed with a slurry of stationary phase and 80:20 (v/v) acetone-20 mM aqueous $\mathrm{NH}_{4} \mathrm{NO}_{3}$ under moderate pressure (380 bars). Both columns were terminated using a quartz wool frit at a final column length of $40.4 \mathrm{~cm}$ for the positional isomer studies and $37.5 \mathrm{~cm}$ for the enantiomer studies.

The liquid chromatographic apparatus used in these studies maintains a constant column flow rate while varying the average pressure $\left(P_{\mathrm{av}}\right)$ on the column. With no added restrictor at the column inlet or outlet, the average column pressure arises solely from the pressure necessary to create mobilephase flow through the column. Therefore, the average column pressure may be approximated as simply one-half of the column inlet pressure since the column outlet is at atmospheric pressure. If restrictors producing equivalent back pressures are added at the inlet and outlet, the column inlet and outlet pressures are increased to the same extent. Al- though the average pressure on the column is increased by the magnitude of the pressure change generated by the added restriction, the column flow rate and pressure gradient remain constant. In this way, the column flow rate was maintained at $1.5 \pm$ $0.04 \mu \mathrm{L} / \mathrm{min}$ throughout these studies, resulting in a column pressure gradient of 100 bars for $50: 50$ $(\mathrm{v} / \mathrm{v})$ methanol-water, 84.2 bars for $20: 80(\mathrm{v} / \mathrm{v})$ methanol-water, 129 bars for $40: 60: 0.9: 0.17$ $(\mathrm{v} / \mathrm{v} / \mathrm{v} / \mathrm{v})$ methanol-water-acetic acid-TEA, and 104 bars for $30: 70: 0.9: 0.17 \quad(\mathrm{v} / \mathrm{v} / \mathrm{v} / \mathrm{v})$ methanol-water-acetic acid-TEA mobile phase. No correlation between pressure and flow rate was observed in these studies, yielding a relative standard deviation in the flow rate of less than $3 \%$ based on replicate void time measurements. Solute retention reversibility after high pressure was evaluated by direct comparison of capacity factors at low pressure after high-pressure perturbation.

\section{RESULTS AND DISCUSSION}

Solute retention in liquid chromatographic separations has been shown to be well described by equilibrium thermodynamics. Although the role of temperature in separations has been widely examined, the other fundamental parameter in equilibrium thermodynamics, pressure, has been long overlooked. The pressure dependence of the equilibrium distribution coefficient of solute between the stationary phase and the mobile phase, $K_{\text {dist }}$, can be derived from the change in Gibbs free energy for solute binding with the stationary phase $\left(\Delta G_{\text {dist }}\right)$ :

$$
\left(\frac{\partial \Delta G_{\text {dist }}}{\partial P}\right)_{T}=-R T\left(\frac{\partial \ln K_{\text {dist }}}{\partial P}\right)_{T}+\Delta n R T \kappa_{S}=\Delta V
$$

where $P$ is pressure and $T$ is temperature. Since the isothermal change with pressure in $\Delta G$ for an equilibrium reaction is directly related to the change in partial molar volume $(\Delta V)$ for that reaction, pressure-induced changes in the distribution coefficient may be directly related to $\Delta V$ upon solute binding with the stationary phase. As Equation (1) indicates, the change in the equilibrium distribution coefficient, $K_{\text {dist }}$, with pressure is mediated by the $\Delta n R T \kappa_{S}$ term, which corrects for changes in molar concentration with pressure due to compression of bulk solvent. The magnitude of this term is therefore related to solvent isothermal compressibility $\left(\kappa_{S}\right)$ as well as the difference in the stoichiometric coefficients of products from reactants $(\Delta n)$. For the separations described here, the compressibilities are 3.8, 3.9, 4.0, and $4.2 \times 10^{-5}$ bar $^{-1}$ for $20,30,40$, and $50 \%(\mathrm{v} / \mathrm{v})$ methanol-water solutions, respectively [14]. 
In liquid chromatographic separations using $\beta$ cyclodextrin bound to a stationary support, the predominant solute retention mechanism is $\beta$-cyclodextrin-solute complexation [3-5]. For this reason, the equilibrium distribution coefficient of the solute between the stationary phase and mobile phase $\left(K_{\text {dist }}\right)$ is directly related to the fundamental equilibrium complexation constant $\left(K_{\text {comp }}\right)$ for $\beta$-cyclodextrin complexation with the solute. This equilibrium complexation constant can therefore be determined by measurement of the chromatographic capacity factor, $k$, the ratio of volumes of the stationary and mobile phases $(\phi)$, and [CD], which is the equilibrium concentration of unbound cyclodextrin:

$$
K_{\text {comp }}=\frac{K_{\text {dist }}}{[\mathrm{CD}]}=\frac{k}{\phi[\mathrm{CD}]}
$$

Therefore, substitution of Equation (2) into the pressure dependence of $K_{\text {dist }}$ described in Equation (1) permits estimation of the change in partial molar volume of complexation directly from the measured change in capacity factor $(k)$ with pressure, assuming that $\phi$ and [CD] do not change significantly with pressure:

$$
-R T\left(\frac{\Delta \ln k}{\Delta P}\right)_{T}+\Delta n R T \kappa_{S}=\Delta V_{\text {comp }}
$$

For the modest pressure conditions encountered in liquid chromatography, the partial differential in Equation (1) can be accurately represented as a simple difference.

The change in molar volume upon complexation $\left(\Delta V_{\text {comp }}\right)$ determined by Equation (3) represents the difference in partial molar volumes of the products and reactants involved in the complexation interaction in their solvated states. Therefore, $\Delta V_{\text {comp }}$ accounts not only for differences in the partial molar volumes of the individual molecules but for their solvation volumes as well. The observed $\Delta V_{\text {comp }}$ may be viewed as the sum of partial molar volume changes for three distinct processes involved in $\beta$-cyclodextrin-solute complexation in liquid solution [15]:

$$
\Delta V_{\text {comp }}=\Delta V_{\text {desolv, solute }}+\Delta V_{\text {desolv }, \mathrm{CD}}+\Delta V_{\text {inclus }}
$$

The first two terms of this expression account for the change in molar volume upon desolvation of that portion of the molecule involved in the binding interaction. Since the desolvation process generally leads to a loss of solvent ordering around the solute, these terms are expected to be positive ( $\Delta V_{\text {desolv, solute }}$ $\left.>0 ; \Delta V_{\text {desolv, CD }}>0\right)$. The final term accounts for mutual solvation of the solute and cyclodextrin that occurs upon inclusion and generally results in a decrease in partial molar volume $\left(\Delta V_{\text {inclus }}<0\right)$. Although modeling studies indicate the possible conformational flexibility of $\beta$-cyclodextrin [16, 17], neutron diffraction measurements in the solvated state show that no significant change in structure is observed [18] For this reason, it is assumed that no significant conformational changes occur upon complexation. As a result, the magnitude of the desolvation terms in Equation (4) relative to the inclusion term determines the direction and magnitude of the overall observed change in solvated molar volume upon complexation. That is, if the desolvation terms are predominant $\left(\Delta V_{\text {comp }}>0\right)$, an increase in pressure is expected to yield a decrease in solute retention, and vice versa if the inclusion term is dominant $\left(\Delta V_{\text {comp }}<0\right)$.

In these studies, we focus on the influence of mobile-phase composition on the pressure dependence of solute retention for liquid chromatographic separations using $\beta$-cyclodextrin bonded phase in the reversed-phase mode. Pressure has been isolated as the only perturbation parameter by maintaining a constant column flow rate while controlling the average pressure on the chromatographic column. The packed capillary columns utilized for all measurements ensure effective temperature control under ambient conditions $\left(T=23 \pm 1^{\circ} \mathrm{C}\right)$. Utilizing this approach, the observed changes in capacity factor with pressure are expected to arise solely from shifts in the equilibrium distribution of solute between the mobile phase and $\beta$-cyclodextrin moieties in the stationary phase. Moreover, since this study employs positional isomers and enantiomers as probes, the effect of pressure on both shape-selective and enantioselective separations is investigated under conditions commonly encountered by chromatographers.

Pressure effects on positional isomer retention. As indicated in Table I, modest pressure has a significant impact on capacity factor for solutes separated in the reversed-phase mode with $\beta$-cyclodextrin stationary phase. For the nitrophenol separations, decreases in capacity factor up to $14 \%$ were observed with a 280-bar increase in pressure. In contrast, the naphthol capacity factors increased $2-3 \%$ or did not change with pressure. The significance of these pressure-induced changes in capacity factor is highlighted by including the propagated error for triplicate measurements in Tables I and II. Not all solutes exhibit statistically significant changes in solute retention with pressure. Indeed, these positional isomers display the full range of pressure dependence, yielding either an increase, a decrease, or no change in solute capacity factors with pressure. 
Table I. Effect of pressure on capacity factor $k$ for reversed-phase separations of the positional isomers of nitrophenol and naphthol on $\beta$-cyclodextrin bonded phase ${ }^{a}$

\begin{tabular}{|c|c|c|c|c|c|}
\hline & $o$-Nitrophenol & $m$-Nitrophenol & $p$-Nitrophenol & $\alpha$-Naphthol & $\beta$-Naphthol \\
\hline \multicolumn{6}{|c|}{ Mobile phase $50: 50(v / v)$ methanol-water } \\
\hline $\begin{array}{c}P_{\mathrm{av}}=55.2 \\
\quad(\mathrm{bars})^{\mathrm{b}}\end{array}$ & $\begin{array}{l}0.585 \\
(0.0052)\end{array}$ & $\begin{array}{c}0.309 \\
(0.0017)\end{array}$ & $\begin{array}{c}1.528 \\
(0.0083)\end{array}$ & $\begin{array}{l}0.498 \\
(0.0021)\end{array}$ & $\begin{array}{c}0.362 \\
(0.0055)\end{array}$ \\
\hline $\begin{array}{l}P_{\mathrm{av}}=323 \\
\quad(\text { bars })^{\mathrm{b}}\end{array}$ & $\begin{array}{c}0.573 \\
(0.0092)\end{array}$ & $\begin{array}{l}0.301 \\
(0.0066)\end{array}$ & $\begin{array}{l}1.45 \\
(0.011)\end{array}$ & $\begin{array}{l}0.513 \\
(0.0038)\end{array}$ & $\begin{array}{l}0.370 \\
(0.0038)\end{array}$ \\
\hline $\begin{array}{l}\text { Percent change in } \\
k\end{array}$ & $\begin{array}{l}-2 \\
(1.8)\end{array}$ & $\begin{array}{l}-3 \\
(2.2)\end{array}$ & $\begin{array}{c}-5.1 \\
(0.9)\end{array}$ & $\begin{array}{r}+3.0 \\
(0.9)\end{array}$ & $\begin{array}{l}+2 \\
(1.8)\end{array}$ \\
\hline $\begin{array}{l}\Delta V_{\text {comp }} \\
\quad\left(\mathrm{cm}^{3} / \mathrm{mol}\right)\end{array}$ & not significant & not significant & $\begin{array}{l}+3.7 \\
(0.86)\end{array}$ & $\begin{array}{l}-4.2 \\
(0.89)\end{array}$ & $\begin{array}{l}-3 \\
(1.9)\end{array}$ \\
\hline \multicolumn{6}{|c|}{ Mobile phase $20: 80(v / v)$ methanol-water } \\
\hline $\begin{array}{l}P_{\mathrm{av}}=42.1 \\
\quad(\text { bars })\end{array}$ & $\begin{array}{l}1.16 \\
(0.018)\end{array}$ & $\begin{array}{c}0.99 \\
(0.022)\end{array}$ & $\begin{array}{c}3.34 \\
(0.036)\end{array}$ & $\begin{array}{c}5.14 \\
(0.053)\end{array}$ & $\begin{array}{l}3.47 \\
(0.055)\end{array}$ \\
\hline $\begin{array}{l}P_{\mathrm{av}}=318 \\
\quad(\text { bars })\end{array}$ & $\begin{array}{l}1.07 \\
(0.015)\end{array}$ & $\begin{array}{c}0.89 \\
(0.016)\end{array}$ & $\begin{array}{c}2.876 \\
(0.0094)\end{array}$ & $\begin{array}{l}5.13 \\
(0.050)\end{array}$ & $\begin{array}{c}3.43 \\
(0.031)\end{array}$ \\
\hline $\begin{array}{l}\text { Percent change in } \\
k\end{array}$ & $\begin{array}{l}-8 \\
(2.0)\end{array}$ & $\begin{aligned}-10 \\
(2.8)\end{aligned}$ & $\begin{aligned}-14 \\
(1.1)\end{aligned}$ & not significant & not significant \\
\hline$\Delta V_{\text {comp }}$ & $\begin{array}{l}+6 \\
(1.9)\end{array}$ & $\begin{array}{r}+9 \\
(2.5)\end{array}$ & $\begin{array}{r}+12 \\
(1.0)\end{array}$ & not significant & not significant \\
\hline
\end{tabular}

${ }^{\mathrm{a}}$ The error shown in parentheses for all capacity factor measurements is the standard deviation of 3 replicate measurements while the error for \% change in $k$ and for $\Delta V$ is the propagated error. Nitrophenol data have been excerpted from ref. 11.

${ }^{\mathrm{b}}$ The naphthol separations with $50: 50(\mathrm{v} / \mathrm{v})$ methanol-water mobile phase were performed in a separate assay for which the average column pressures were 49.0 and 285 bars, respectively.

Table II. Effect of pressure on capacity factor $k$ for reversed-phase chiral separations of hexobarbital and mephobarbital on $\beta$-cyclodextrin bonded phase ${ }^{a}$

\begin{tabular}{|c|c|c|c|c|}
\hline & Hexobarbital 1 & Hexobarbital 2 & Mephobarbital 1 & Mephobarbital 2 \\
\hline \multicolumn{5}{|c|}{ Mobile phase $40: 60: 0.9: 0.17(v / v / v / v)$ methanol-water-acetic acid-TEA, $p H 4.2^{b}$} \\
\hline $\begin{array}{l}P_{\mathrm{av}}=64.3 \\
\quad(\text { bars })\end{array}$ & $\begin{array}{c}0.917 \\
(0.0039)\end{array}$ & $\begin{array}{l}1.051 \\
(0.0034)\end{array}$ & $\begin{array}{c}0.670 \\
(0.0007)\end{array}$ & $\begin{array}{l}0.755 \\
(0.0014)\end{array}$ \\
\hline $\begin{array}{l}P_{\mathrm{av}}=306 \\
\quad(\mathrm{bars})\end{array}$ & $\begin{array}{l}1.02 \\
(0.013)\end{array}$ & $\begin{array}{l}1.17 \\
(0.011)\end{array}$ & $\begin{array}{l}0.742 \\
(0.0062)\end{array}$ & $\begin{array}{l}0.829 \\
(0.0092)\end{array}$ \\
\hline $\begin{array}{l}\text { Percent change in } \\
k\end{array}$ & $\begin{array}{l}+11 \\
\quad(1.5)\end{array}$ & $\begin{array}{l}+11 \\
(1.1)\end{array}$ & $\begin{array}{r}10.7 \\
(0.9)\end{array}$ & $\begin{array}{l}+10 \\
(1.2)\end{array}$ \\
\hline $\begin{array}{l}\Delta V_{\text {comp }} \\
\quad\left(\mathrm{cm}^{3} / \mathrm{mol}\right)\end{array}$ & $\begin{aligned}-12 \\
(1.4)\end{aligned}$ & $\begin{array}{r}-12 \\
(1.1)\end{array}$ & $\begin{array}{r}-11.5 \\
(0.9)\end{array}$ & $\begin{array}{r}-10 \\
(1.2)\end{array}$ \\
\hline \multicolumn{5}{|c|}{ Mobile phase $30: 70: 0.9: 0.17(v / v / v / v)$ methanol-water-acetic acid-TEA, pH 4.0} \\
\hline $\begin{array}{l}P_{\mathrm{av}}=52.2 \\
\quad(\text { bars })\end{array}$ & $\begin{array}{l}2.46 \\
(0.048)\end{array}$ & $\begin{array}{l}2.84 \\
(0.068)\end{array}$ & $\begin{array}{l}1.97 \\
(0.017)\end{array}$ & $\begin{array}{l}2.24 \\
(0.021)\end{array}$ \\
\hline $\begin{array}{l}P_{\mathrm{av}}=307 \\
\quad(\text { bars })\end{array}$ & $\begin{array}{c}2.60 \\
(0.043)\end{array}$ & $\begin{array}{c}3.07 \\
(0.015)\end{array}$ & $\begin{array}{c}2.07 \\
(0.017)\end{array}$ & $\begin{array}{c}2.38 \\
(0.024)\end{array}$ \\
\hline $\begin{array}{l}\text { Percent change in } \\
k\end{array}$ & $\begin{array}{l}+6 \\
(2.6)\end{array}$ & $\begin{array}{l}+8 \\
(2.5)\end{array}$ & $\begin{array}{l}+5 \\
(1.2)\end{array}$ & $\begin{array}{l}+6 \\
(1.4)\end{array}$ \\
\hline$\Delta V_{\mathrm{comp}}\left(\mathrm{cm}^{3} / \mathrm{mol}\right)$ & $\begin{array}{l}-6 \\
(2.5)\end{array}$ & $\begin{array}{l}-8 \\
(2.4)\end{array}$ & $\begin{array}{l}-6 \\
(1.2)\end{array}$ & $\begin{array}{l}-6 \\
(1.3)\end{array}$ \\
\hline
\end{tabular}

${ }^{\mathrm{a}}$ The error shown in parentheses for all capacity factor measurements is the standard deviation of 3 replicate measurements while the error for $\%$ change in $k$ and for $\Delta V$ is the propagated error.

${ }^{\mathrm{b}}$ The retention data for this mobile phase have been excerpted in part from ref. 12 . 
Moreover, these pressure-induced perturbations in capacity factor are shown to be dependent on mobile-phase composition. These mobile-phase effects may be understood more clearly based on changes in molar volume upon complexation $\left(\Delta V_{\text {comp }}\right)$ determined from the pressure dependence of solute capacity factor [Equation (3)]. For these positional isomers, chromatographic retention measurements at different pressures indicate a more positive change in molar volume upon complexation with increasing water content in the mobile phase (Table I). The nitrophenol isomers exhibit a negligible or slightly positive $\Delta V_{\text {comp }}$ in the $50: 50(\mathrm{v} / \mathrm{v})$ methanol-water mobile phase, with the $\Delta V_{\text {comp }}$ becoming more positive upon increasing the water content of the mobile phase to $20: 80(\mathrm{v} / \mathrm{v})$ methanol-water. In contrast, the naphthol isomers show a negative $\Delta V_{\text {comp }}$ when separated using a $50 \%$ $(\mathrm{v} / \mathrm{v})$ aqueous mobile phase yet also exhibit a more positive $\Delta V_{\text {comp }}$ when the water content of the mobile phase is increased to $80 \%(\mathrm{v} / \mathrm{v})$. Thus, regardless of whether $\Delta V_{\text {comp }}$ is positive or negative, an increase in water content over this range results in a more positive overall $\Delta V_{\text {comp }}$. Demonstrated here for two methanol-water mobile phases, this dependence on solvent composition may not be consistent over the entire range of mixtures. Accordingly, further studies are needed to elucidate the exact dependence of the overall $\Delta V_{\text {comp }}$ on solvent composition.

Since changes in the bulk compressibility of the mobile phase with changing composition are already included in estimation of $\Delta V_{\text {comp }}$ from Equation (3), the observed changes in $\Delta V_{\text {comp }}$ with mobile-phase composition may be evaluated based on expected contributions to the partial molar volume during the complexation process. Based on Equation (4), shifts in the magnitude and sign of the change in molar volume upon complexation must arise from changes in the relative contributions of desolvation and inclusion in the overall $\Delta V_{\text {comp }}$. In order for more positive $\Delta V_{\text {comp }}$ to be observed with increasing water content, the $\Delta V_{\text {desolv, solute }}$ and $\Delta V_{\text {desolv, CD }}$ contributions arising from desolvation of the solute and cyclodextrin must become more positive and/or the $\Delta V_{\text {inclus }}$ contribution from the inclusion step must become less negative with increased water content of the mobile phase. Unfortunately, these determinations yield the overall changes in molar volume upon complexation and do not allow isolation of the individual contributions to the complexation process. Nonetheless, the composition of the mobile phase has a significant effect on the pressure dependence of solute retention of positional isomers.
Pressure effects on enantioselective retention. In addition to the separation of positional isomers, $\beta$-cyclodextrin bonded phase is also commonly employed for chiral separations in the reversed-phase mode. As shown in Table II, modest pressure is shown to significantly affect enantioselective retention as well. For this study, the retention properties of the structurally similar sedatives hexobarbital and mephobarbital have been examined:
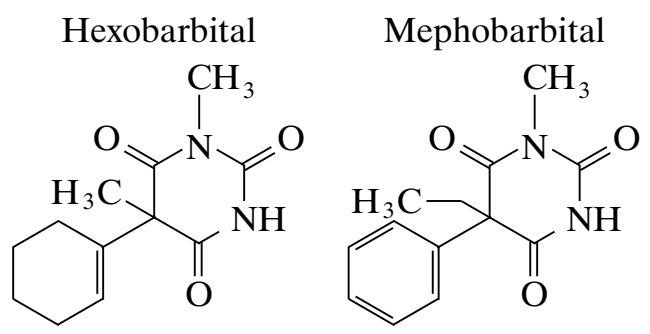

Both enantiomers of hexobarbital and mephobarbital exhibit increases in capacity factor which range from +5 to $+11 \%$ with an increase in pressure. In every case, these capacity factor shifts were used to estimate decreases in molar volume upon complexation $\left(\Delta V_{\text {comp }}\right)$ that were similar in magnitude for enantiomeric pairs.

These pressure-induced perturbations in enantiomeric capacity factor are also dependent on mobile-phase composition. Consistent with the positional isomer separations, the enantioselective retention measurements at different pressures shown in Table II indicate a change to more positive molar volumes $\left(\Delta V_{\text {comp }}\right)$ with increasing water content in the mobile phase. Again, this trend indicates that the $\Delta V_{\text {desolv, solute }}$ and $\Delta V_{\text {desolv, CD }}$ contributions arising from desolvation become more positive and/or the $\Delta V_{\text {inclus }}$ contribution becomes less negative with increased water content of the mobile phase. These pressure-induced shifts in enantioselective retention by $\beta$-cyclodextrin bonded phase have important implications for pressure-induced changes in chiral resolution [12] for this challenging class of separations.

At this point it is tempting to correlate the observed changes in $\Delta V_{\text {comp }}$ with solvent composition directly to interaction energetics. However, a greater change in the Gibbs free energy of interaction $\left(\Delta G_{\text {comp }}\right)$ and concomitant increase in solute capacity factor does not infer a greater change in solvated molar volume upon interaction $\left(\Delta V_{\text {comp }}\right)$. It is the change in $\Delta G$ with pressure that gives rise to $\Delta V$ [Equation (2)]. Demonstration of the lack of a relationship between the magnitudes of $\Delta G$ and $\Delta V$ can be seen in comparing the nitrophenol and naph- 
thol capacity factors in the $20: 80(\mathrm{v} / \mathrm{v})$ methanolwater mobile phase (Table I). Although the naphthols exhibit larger capacity factors (higher $\Delta G$ ), the $\Delta V$ upon complexation is significantly less for the naphthols than for the nitrophenols. However, the exact nature of the solvent-mediating effect on pressure-dependent retention remains unclear. Studies are presently underway to assess this pressure dependence over the full range of methanol-water compositions as well as the impact for acetonitrilebased mobile phases.

\section{ACKNOWLEDGMENT}

The kind gift of the $\beta$-cyclodextrin stationary phase from the Advanced Separations Technology Corp. is gratefully acknowledged.

\section{REFERENCES}

1. M. L. Bender and M. Komiyama, Cyclodextrin Chemistry (Springer-Verlag, Berlin, 1978).

2. W. L. Hinze, Sep. Purif. Methods 10, 159 (1981).

3. K. Fujimura, T. Ueda, and T. Ando, Anal. Chem. 55, 446 (1983).

4. Y. Kawaguchi, M. Tanaka, M. Nakae, K. Funazo, and T. Shono, Anal. Chem. 55, 1852 (1983).
5. D. W. Armstrong and W. DeMond, J. Chromatogr. Sci. 22, 411 (1984).

6. D. W. Armstrong, U.S. Patent 4,539,999, 1985.

7. M. Tanaka, Y. Kawaguchi, M. Nakae, Y. Mizobuchi, and T. Shono, J. Chromatogr. 299, 341 (1984).

8. M. D. Beeson and G. Vigh, J. Chromatogr. 634, 197 (1993).

9. K. Cabrera and D. Lubda, J. Chromatogr. 666, 433 (1994).

10. M. C. Ringo and C. E. Evans, J. Phys. Chem. B 101, 5525 (1997).

11. M. C. Ringo and C. E. Evans, Anal. Chem. 69, 643 (1997)

12. M. C. Ringo and C. E. Evans, Anal. Chem. 69, 4964 (1997).

13. M. Martin, G. Blu, and G. Guiochon, J. Chromatogr. Sci. 11, 641 (1973).

14. R. E. Gibson, J. Am. Chem. Soc. 57, 1551 (1935).

15. Y. Sueishi, N. Nishimura, K. Hirata, and K. Kuwata, J. Phys. Chem. 95, 5359 (1991).

16. K. B. Lipkowitz, J. Org. Chem. 56, 6357 (1991).

17. B. Mayer and G. Köhler, THEOCHEM 363, 217 (1996).

18. C. Betzel, W. Saenger, B. E. Hingerty, and G. M. Brown, J. Am. Chem. Soc. 106, 7545 (1984). 